\title{
O CONCEITO DE VERDADE NA FILOSOFIA Sistemático-Estrutural DE LORENZ PUNTEL
}

\author{
EDNILSON GOMES MATIAS
}

\begin{abstract}
This work presents the concept of truth developed in Lorenz Puntel's book "Structure and Being: a Theoretical Framework for a Systematic Philosophy". The language as mean of expressibility of the world is analyzed from its three levels of determination (contextual, pragmatic and semantic) and from its three levels of fundamental structures (formal, semantic and ontological). Puntel argue the thesis that semantic and ontology are mutually implicated and consequently the reference to reality presents itself as central theme to the conception of truth developed in the context of structural-systematic philosophy.
\end{abstract}

Keywords: Puntel; structural-systematic philosophy; truth; language.

\section{Introdução}

Em Estrutura e Ser, Lorenz Puntel (2008, p.12) apresenta sua filosofia sistemáticoestrutural enquanto "teoria das estruturas universais do universo do discurso ilimitado". Visto que essa é uma definição provisória desenvolvida progressivamente ao longo da obra, é preciso elucidar conceitos como: "filosofia sistemática", "teoria", "estrutura" e "universo do discurso".

A filosofia pode ser considerada sistemática (de caráter abrangente ou universal) em dois sentidos: um principal, enquanto abordagem integradora entre os componentes temáticos; e um secundário, enquanto abordagem não orientada historicamente. A filosofia sistemático-estrutural retoma esse sentido principal de sistemático através da conexão entre a dimensão das estruturas (linguagem) e a dimensão do universo do discurso (mundo, realidade, Ser).

Uma teoria consiste em um discurso metódico e rigorosamente ordenado que tem por objetivo a apresentação do mundo. A filosofia é apresentada como uma atividade estritamente teórica e, portanto, destaca-se a centralidade da linguagem enquanto instância de expressabilidade de toda teoria.

O conjunto de tudo o que pode ser compreendido/explicado pela teoria constitui a dimensão do universo do discurso. Visto que a filosofia sistemático-estrutural possui um caráter abrangente/universal, a ela pertence um universo do discurso ilimitado. Isso significa que tudo o que pode ser linguisticamente articulado faz parte do seu "dado abrangente", ou seja, é candidato à teoria ou à verdade.

Todos os elementos teóricos ("conceito", "significado", "valor semântico", "categoria”, "proposição", “estados de coisas”, “objeto", "fato”, "regra lógica” etc.) são

Principia 19(3): 453-463 (2015).

Published by NEL — Epistemology and Logic Research Group, Federal University of Santa Catarina (UFSC), Brazil. 
reduzidos ao conceito geral de estrutura, o qual designa tudo o que uma teoria explicita. Nesse sentido, o termo "estrutura" deve ser compreendido como inter-relação ordenada de elementos de uma mesma entidade.

O conjunto dos pressupostos irrenunciáveis inerentes a toda e qualquer teoria é chamado de quadro referencial teórico. Para que uma teoria possa ser compreendida, é necessário que ela seja situada dentro de um quadro teórico. Há uma pluralidade de quadros teóricos, cada um dos quais desenvolve a verdade em diferentes níveis. $\mathrm{O}$ objetivo de Estrutura e Ser é desenvolver o melhor quadro referencial teórico possível para uma filosofia sistemática.

\section{A centralidade da linguagem}

\subsection{Planos de determinação da linguagem}

Puntel (2008, p.196) apresenta o seguinte fato linguístico original: a linguagem, em seu sentido mais geral de sistema de signos, é completamente indeterminada ou subdeterminada. A determinação da linguagem se desenvolve em três planos: o contextual-cotidiano, o pragmático e o semântico.

O primeiro plano de determinação da linguagem é o contextual-cotidiano (Puntel 2008, p.198), no qual a linguagem "natural" é usada para a comunicação intersubjetiva, ou seja, promove o entendimento mútuo entre os usuários da linguagem. Nesse plano a determinação completa da linguagem é estabelecida por uma dimensão externa: o contexto cotidiano de comunicação.

O segundo plano de determinação da linguagem é o pragmático-linguístico (Puntel 2008, p.199), no qual há uma reflexão acerca da utilização da linguagem natural no contexto cotidiano de comunicação. A linguagem perde sua determinação externa (proveniente do contexto de comunicação) e adquire uma determinação "mista" (externa e interna à linguagem). Nesse plano, a determinação da linguagem é estabelecida tanto pela ação (fator externo) quanto pela articulação linguística dessa ação (fator interno).

O terceiro plano de determinação da linguagem é o semântico (Puntel 2008, p.200), no qual a determinação da linguagem ocorre pela anteposição (implícita ou explícita) do operador de verdade "é verdade(iro) que..." (por exemplo: "A neve é branca"). O operador "é verdade(iro) que" não faz referência a fatores externos à linguagem: contextos cotidianos, sujeitos, falantes, agentes, ações etc. Nesse sentido, Puntel (2008, p.200-1) sustenta que o operador de verdade e o vocabulário semântico promovem a determinação puramente interna da linguagem, visto que nesse nível semântico a linguagem interpreta a si própria.

Principia 19(3): 453-463 (2015). 


\subsection{Estruturas fundamentais da linguagem}

Enquanto as teorias científicas desenvolvem estruturas particulares que articulam um universo do discurso limitado, a filosofia sistemático-estrutural desenvolve estruturas universais que articulam o universo do discurso ilimitado. As estruturas fundamentais da linguagem são desenvolvidas em três planos: as estruturas formais, as estruturas semânticas e as estruturas ontológicas.

O plano das estruturas formais fundamentais compreende duas disciplinas não filosóficas autônomas, a saber, lógica e matemática. As estruturas formais são as mais abstratas e universais e constituem a dimensão articuladora, ou seja, a configuração básica do discurso.

O plano das estruturas semânticas estabelece a relação entre a linguagem e o mundo. A semântica tradicional geralmente se baseia no princípio da composicionalidade semântica (PCPS): "o significado (ou o valor semântico) da sentença é uma função dos significados (ou dos valores semânticos) de seus componentes subsentenciais" (Puntel 2008, p.247). Conforme este princípio, as sentenças são compostas por sujeito e predicado (seus componentes subsentenciais) cada um com seu próprio significado (ou valor semântico). Na filosofia analítica, o sujeito da sentença é chamado de "objeto (real)", o qual consiste numa outra expressão da categoria de "substância" própria da ontologia tradicional.

A substância designa "algo" ("substrato") a respeito do qual podem ser predicadas (atribuídas) certas determinações (propriedades e/ou relações). Mas se todas as determinações forem abstraídas da substância, restará apenas um substrato indeterminado, vazio de sentido, portanto, ininteligível. Visto que esta categoria da substância é inaceitável, deve-se rejeitar a semântica e a ontologia tradicionais, baseadas no princípio composicional. Uma das teses centrais de Estrutura e Ser (Puntel 2008, p.7) sustenta que semântica e ontologia se implicam mutuamente. Uma vez rejeitada a semântica composicional, Puntel desenvolve uma nova semântica que se funda no princípio do contexto (PCT): "somente no contexto de uma sentença as expressões linguísticas possuem valor semântico" (Puntel 2008, p.266). As sentenças dessa nova semântica contextual não possuem nem sujeito nem predicado e são chamadas "sentenças primas". Essas sentenças primas são antecedidas pelo operador teórico "é o caso que...", o qual proporciona à sentença um caráter absoluto, na medida em que não faz referência a quaisquer fatores externos, mas apenas ao próprio estatuto da teoria enquanto tal. Deste modo, a semântica e a ontologia contextuais propostas por Puntel (2008; 2001a; 1993) cumprem de modo mais rígido as exigências de uma teoria filosófica.

O plano das estruturas ontológicas, portanto, constitui o estatuto definitivo das estruturas semânticas. As sentenças (entidades linguísticas) expressam proposições (entidades não linguísticas), ou seja, conteúdos informacionais. Nesse sentido, as

Principia 19(3): 453-463 (2015). 
sentenças primas expressam proposições primas, isto é, que não pressupõem sujeito (termo singular, nome próprio) e predicado como fatores semanticamente relevantes. Uma proposição prima verdadeira é idêntica a uma entidade do mundo, isto é, a um fato primo, o qual não pressupõe uma substância que possui propriedades. Isso significa que uma proposição prima (semântica) completamente determinada corresponde a um fato primo (ontológico). O termo "fato" expressa a totalidade dos elementos do mundo, da realidade, do ser. Todas as entidades do mundo são compreendidas como configurações de fatos primos simples ou complexos. Deste modo, o mundo é a totalidade dos fatos primos configurados em toda sua variedade. A única categoria ontológica da filosofia sistemático estrutural é o fato primo compreendido como estrutura ontológica prima.

\section{O conceito de verdade}

\subsection{Verdade(iro) como predicado e como operador}

De acordo com Puntel, verdade(iro) pode ser utilizado como predicado ou como operador. O conceito de verdade(iro) como predicado possibilita duas interpretações do "predicado de verdade" (Puntel 2008, p.193-5). Na primeira forma, "verdade(iro)" aparece como predicado de uma sentença ("a sentença $p$ é verdadeira"). Tomemos como exemplo a sentença "A neve é branca". Se aplicarmos a ela a primeira forma do predicado de verdade temos: "[A sentença] 'A neve é branca' é verdadeira". Na segunda forma, "verdade(iro)" diz respeito a proposição expressa pela sentença formada com a partícula "que", ou seja, "a proposição que $p$ é verdadeira". O predicado de verdade aplicado de acordo com a segunda forma fica assim: "[A proposição] que 'A neve é branca' é verdadeira".

O conceito de "verdade(iro)" como operador é utilizado como prefixo de uma sentença, por exemplo, "É verdade que 'A neve é branca", sendo "é verdade que..." o operador. É preciso destacar a principal diferença entre "verdade(iro)" como predicado e "verdade(iro)" como operador. No primeiro caso, "verdade(iro)" é aplicado a nomes ou termos singulares, mais precisamente, a sentenças nominalizadas. No segundo caso, o operador "é verdade que..." não se aplica a sentenças nominalizadas, mas sim constitui sentenças autênticas completas: "é verdade que (:) a neve é branca". Puntel (2008, p.193) afirma que essa diferença, embora pareça irrelevante, resulta em concepções semânticas e ontológicas distintas. A utilização de "verdade(iro)" como predicado implica uma semântica "composicional", que resulta em uma ontologia da substância - a qual rejeitamos anteriormente. Por outro lado, a utilização de "verdade(iro)" como operador está de acordo com uma semântica e uma ontologia baseadas no princípio do contexto.

Principia 19(3): 453-463 (2015). 


\subsection{A ideia fundamental de verdade}

O tema da verdade está presente em diversas obras de Puntel (2009; 2008; 2001b; 1999) e constitui uma questão central para o desenvolvimento da filosofia sistemático-estrutural. Uma primeira formulação da ideia fundamental de verdade pode ser apresentada nos seguintes termos: "verdade(iro)" designa, por um lado, o processo de determinação da linguagem e, por outro, a própria linguagem plenamente determinada. Isso significa que o operador "é verdade que" designa tanto a transposição do estatuto indeterminado (ou subdeterminado) da linguagem para um estatuto completamente determinado, quanto o resultado dessa transposição, a saber, a determinação completa da linguagem.

Puntel (2008, p.298) afirma que "o status completamente determinado da linguagem visa a nada mais nada menos que a dimensão ontológica total da linguagem". Para explicitar essa determinação plena da linguagem, Puntel apresenta a interpretação de Quine acerca do esquema da verdade de Tarski. Façamos agora o mesmo percurso argumentativo de Puntel.

Quine (1990, p.80), citado por Puntel (2008, p.298, nota de rodapé 39), defende uma teoria de "des-citação da verdade" com o seguinte teor: "Atribuição de verdade simplesmente cancela as aspas da citação. Verdade é des-citação (disquotation)". De acordo com Puntel, a assunção de "verdade(iro)" enquanto função de des-citação corresponde ao esquema da verdade de Tarski, o qual pode ser formulado assim: ' $p$ ' é verdadeira $\leftrightarrow p$ ([a sentença] "a neve é branca" é verdadeira se e somente se a neve é branca). Quine (1970, p.11), citado por Puntel (2011, p.171), apresenta a relação entre "verdade(iro)" e "realidade" na seguinte passagem: "A verdade depende da realidade [...]. O predicado 'verdadeiro' serve para, de certo modo, apontar para a realidade através da sentença [...]. A realidade continua sendo o único xis da questão (really is still the whole point)". Puntel concorda com a compreensão de Quine de que a "realidade" é a questão central no caso do predicado "verdadeiro".

Quine (1970, p.10), citado por Puntel (2008, p.298, grifo do autor), interpreta o esquema da verdade de Tarski da seguinte maneira: "A sentença 'A neve é branca' é verdadeira, como Tarski nos ensinou, se e somente se a neve real for realmente branca". No entanto, de acordo com Puntel, essa interpretação de Quine está incorreta. O esquema da verdade de Tarski (1983, p.155), “ $p$ ' é verdadeira $\leftrightarrow p$ ”, não indica claramente uma referência ao mundo, ou seja, a sentença ao lado direito da equivalência não pode ser considerada, sem uma determinação mais precisa, como falando sobre o mundo. A referência ao mundo só é indicada por Quine ao introduzir os termos "real" e "realmente" ao lado direito da equivalência. Portanto, embora não esteja correta, a interpretação de Quine acerca do esquema da verdade de Tarski introduz uma questão central: a referência à realidade. É essa referência à realidade introduzida por Quine que possibilita a determinação da linguagem. Essa reinterpre- 
tação quineana do esquema da verdade de Tarski pode ser formulada da seguinte maneira: ' $p$ ' é verdadeiro $\leftrightarrow$ realmente: $p$ ([a sentença] "a neve é branca" é verdadeira se e somente realmente: a neve é branca).

Tarski (1983, p.155), citado por Puntel (2008, p.300, grifo do autor), apresenta uma compreensão intuitiva (informal) de verdade que deu margem ao erro de Quine: "uma sentença verdadeira é aquela que diz que as coisas se comportam assim e assim e as coisas se comportam justamente assim e assim". De acordo com Puntel (2008, p.300), a palavra "justamente" [em alemão: eben; em inglês: in fact, indeed] articula a transposição da sentença indeterminada "as coisas se comportam assim e assim" para a sentença plenamente determinada "as coisas se comportam justamente assim e assim". Sem o termo "justamente", as sentenças seriam uma repetição sem sentido. De acordo com Puntel, o termo "justamente" de Tarski corresponde ao termo "real/realmente" de Quine, ou seja, promove a referência à realidade. No entanto, Tarski não articulou de forma clara essa compreensão intuitiva de verdade, o que ocasionou o erro de Quine.

\subsection{Teorias prossentencial e persentencial da verdade}

Uma importante proposta atual para a explicação do operador de verdade é a "teoria prossentencial da verdade". Esta teoria compreende "verdade(iro)" não como um predicado, mas como um fragmento de uma prossentença. Prossentença é uma expressão que tem relação com outra expressão ocorrida anteriormente. Esta relação entre expressões tem um caráter anafórico, pois remete para uma ocorrência anterior. Neste sentido, a verdade se reporta a uma sentença antecedente. O operador "é verdade(iro) que..." serve para remeter a uma sentença já ocorrida. Por exemplo: "Considere: a neve é branca. Isto é verdadeiro" (Puntel 2008, p.303).

Puntel se contrapõe a esta "teoria prossentencial/anafórica da verdade" com sua "teoria persentencial/catafórica da verdade". Persentença é uma sentença a ser aperfeiçoada, completada, completamente determinada. Nesta "teoria persentencial/catafórica", numa relação entre duas sentenças, a primeira tem um estatuto ainda subdeterminado, enquanto a segunda tem um estatuto completamente determinado. Esta nova teoria preserva a concepção de "verdade(iro)" não como um predicado, mas sim como um operador. A diferença é que não trata de prossentença ou relação anafórica (que remete a uma sentença anterior), mas sim de persentença ou relação catafórica (que remete a uma sentença a ser completada). O operador de verdade na teoria persentencial tem como função a determinação completa das sentenças e/ou proposições. Por exemplo: "é verdade(iro) que $p$ ['a neve é branca']".

Principia 19(3): 453-463 (2015). 


\section{O relativismo da verdade}

\subsection{Relativismo moderado da verdade}

A teoria da verdade deve enfrentar duas teses centrais de Estrutura e Ser (Puntel 2008, p.321): 1) todos os enunciados teóricos, inclusive os verdadeiros, são propostos em conformidade com um quadro teórico; 2) há uma pluralidade de quadros referenciais teóricos. Consequentemente, a verdade de toda sentença/proposição é relativa a um quadro teórico e disso emerge a questão do relativismo da verdade.

De acordo com um relativismo irrestrito (total ou radical), todas as verdades são essencialmente relativas. No entanto, essa tese abriga uma antinomia. Ela se funda numa proposição que, embora tenha um caráter absoluto, implica uma relatividade: se "toda verdade é relativa" é uma proposição verdadeira, então a própria verdade dessa proposição é relativa. Consequentemente, a verdade da tese do relativismo irrestrito é uma verdade relativa (Puntel 2008, p.321).

Essa inconsistência resulta de uma concepção errônea de uma "verdade absoluta" compreendida como uma verdade não relativa a nenhum quadro teórico. Puntel (2008, p.322) evita a inconsistência da tese relativista irrestrita ao defender uma forma moderada de relativismo da verdade segundo a qual "todas as verdade são relativas a algum (pelo menos um) quadro teórico". Nesse sentido, "verdade absoluta" é compreendida como verdade válida relativamente a todos os quadros teóricos.

Em suma: enquanto o relativismo irrestrito da verdade compreende "verdade absoluta" como verdade independente de todo e qualquer quadro teórico, o relativismo moderado da verdade compreende "verdade absoluta" como verdade em conformidade com todo e qualquer quadro teórico, isto é, verdade válida relativamente a todo e qualquer quadro teórico. Deste modo, o relativismo moderado de Puntel evita a autocontraditoriedade do relativismo irrestrito da verdade.

\subsection{Problemas da concepção de verdade absoluta}

O relativismo moderado parte da compreensão da verdade absoluta como verdade válida relativamente a todos os quadros teóricos (Puntel 2008, p.322-6). Embora esse conceito pareça "inacessível" por ser muito abrangente, ele pode ser compreendido, visto que há conceitos "demasiado grandes" na matemática que podem ser entendidos e até definidos. Mas esse conceito de verdade absoluta é aplicável (realizável)? Sobre a aplicabilidade do conceito de verdade absoluta, há dois problemas: um de princípio e um específico.

O primeiro, o problema de princípio, é que este conceito é muito abrangente para ser "concretizado" e, portanto, não há um "lugar" determinado para ele no empreendimento teórico: como o conceito de verdade absoluta pode ser aplicável em todos 
os quadros teóricos se não é possível apreender e articular cada um dos quadros teóricos? A resposta de Puntel (2008, p.323) a esse problema de princípio consiste em admitir o conceito de verdade absoluta como um conceito-limite ou como uma ideia reguladora. O conceito de verdade absoluta "regula" todo o empreendimento teórico na medida em que aclara os grandes nexos filosóficos ao indicar o "lugar" sistemático dos temas articuladores e dos enunciados propostos.

O segundo, o problema específico da aplicabilidade do conceito de verdade absoluta, é consequência da concepção aqui desenvolvida de quadro teórico: como articular verdades absolutas (relativas a todos os quadros teóricos) quando se pressupõe ou se aplica um determinado quadro teórico (como, por exemplo, o da filosofia sistemático-estrutural)? A resposta de Puntel (2008, p.324) a esse problema específico se apoia no caráter aberto e na incompletude da filosofia sistemático-estrutural. O quadro teórico da filosofia sistemático-estrutural "sempre já se encontra além de si mesmo" (Puntel 2008, p.324), ou seja, está inserido dentro de um "metaquadro teórico" mais abrangente. Isso significa que o quadro teórico aqui desenvolvido é um entre muitos outros na totalidade de metaquadros teóricos reais e possíveis.

De acordo com Puntel (2008, p.324) o grau de inteligibilidade do teórico/filósofo tem um alcance maior que o quadro teórico por ele utilizado: "o teórico sempre já se encontra em uma 'metadimensão' relativamente ao 'seu' [...] quadro teórico". A concepção de verdade absoluta aqui desenvolvida (enquanto válida relativamente a todos os quadros teóricos) apresenta um "metastatus" em relação ao quadro teórico aplicado. Esse "metastatus" da verdade absoluta abrange todos os quadros teóricos e é resultado de toda a capacidade de inteligibilidade do teórico/filósofo. Nesse sentido, o relativismo moderado da filosofia sistemático-estrutural não exclui a possibilidade de assumir verdades absolutas no sentido de verdades em conformidade com (ou válidas relativamente a) todos os quadros teóricos.

\subsection{Um exemplo de verdade absoluta}

Do que foi exposto, resultam duas questões sobre as verdades absolutas (no sentido aqui pressuposto): 1) “como são apreendidas ou articuladas" e 2) “quais são elas?".

Verdades absolutas não podem, a rigor, ser apreendidas/articuladas como verdades da filosofia sistemático estrutural, mas apenas como parte da metadimensão dessa filosofia. No entanto, essas mesmas verdades, sem o qualificativo "absoluto", podem ser denominadas axiomas dessa filosofia. Puntel (2008, p.325-6) responde a primeira questão ("como verdades absolutas são apreendidas/articuladas?") supondo a criação de um (meta)quadro teórico. O teórico/filósofo pode elaborar um (meta)quadro teórico (ainda subdeterminado) dentro do qual propõe enunciados com o qualificativo "absolutamente verdadeiro".

A segunda questão (“quais são essas verdades absolutas?”) é respondida por Pun-

Principia 19(3): 453-463 (2015). 
tel (2008, p.326) com base nas "verdades" lógicas e metafísicas abrangentes: por exemplo, os princípios da não-contradição, da coerência universal, da unidade de toda a realidade, da razão suficiente e muitos outros.

Tomemos como exemplo o princípio da não-contradição, considerado "verdade absoluta" por Puntel (2008, p.326) e questionado com base na lógica paraconsistente por Guido Imaguire (2008, p.289) na sua resenha do livro Estrutura e Ser. De acordo com uma formulação sentencial/proposicional, o princípio da não-contradição sustenta: “ $\neg(p \wedge \neg p)$ : é excluído que se possa admitir (a sentença/proposição) $p$ como válida/verdadeira e (ao mesmo tempo) a negação de $p$ como válida/verdadeira" (Puntel 2013, p.55). Para tratar do problema da contradição, Puntel (2013, p.55) apresenta o princípio ECQ (ex contradictione quodlibet), conhecido como princípio da explosão ou Regra de Duns Scotus, segundo o qual "de algo contraditório (i. é, de duas sentenças ou proposições contraditórias) segue qualquer coisa". Isso significa que qualquer coisa pode ser inferida de uma contradição e, por esse motivo, concepções/teorias/sistemas lógicos que admitem contradições caem na trivialidade. É necessário distinguir o sentido estrito (forte) do sentido amplo (fraco) do conceito de "contradição". As lógicas paraconsistentes sustentam que nem toda contradição (no sentido amplo/fraco) resulta em trivialidade. Por outro lado, admitem que pode haver concepções/teorias/sistemas triviais. Isso significa que reconhecem que pode haver contradições (no sentido estrito/forte) das quais segue trivialidade e para as quais vale o princípio ECQ. De acordo com Puntel (2013, p.56), o princípio ECQ "vale irrestritamente no caso da contradição estrita/forte, mas não necessariamente no caso da contradição ampla/fraca".

Todas as lógicas, inclusive as paraconsistentes, rejeitam concepções/teorias/sistemas triviais, portanto, admitem implicitamente que há contradições que resultam em trivialidades. Isso significa que todas as lógicas, inclusive as paraconsistentes, aceitam o sentido estrito/forte do conceito de contradição. Dito de outra forma, a contradição no sentido estrito/forte é aceita em todos os quadros teóricos. Nesse sentido, Puntel (cf. 2013, p.56) sustenta que se considerarmos o conceito de contradição, em seu sentido estrito/forte, o princípio de não-contradição é valido em conformidade com todos os quadros referenciais teóricos, portanto, emerge como uma verdade absoluta.

\section{Considerações finais}

Na obra Estrutura e Ser, Lorenz Puntel apresenta a linguagem como instância de expressabilidade do mundo e como dimensão articuladora de teorias. O estudo sobre a linguagem inicia com a apresentação de seus níveis de determinação e de suas estruturas fundamentais. Os três níveis de determinação da linguagem são o contextual,

Principia 19(3): 453-463 (2015). 
o pragmático e o semântico. No plano contextual, a linguagem recebe uma determinação externa, proveniente do contexto de comunicação. No plano pragmático, a linguagem recebe uma determinação ao mesmo tempo externa (da ação) e interna (do proferimento da ação). No plano semântico, a linguagem recebe uma determinação puramente interna, na medida em que interpreta a si mesma, sem referência a contextos, nem a ações ou a agentes etc. Por esse motivo, Puntel considera o plano semântico o mais apropriado para o desenvolvimento de teorias.

A linguagem, enquanto campo de articulação das teorias, deve ser investigada a partir de suas estruturas fundamentais: as formais, as semânticas e as ontológicas. O plano das estruturas formais é o mais abstrato e constitui a configuração básica do discurso. $\mathrm{O}$ plano das estruturas semânticas estabelece a relação entre a linguagem e o mundo. O plano das estruturas ontológicas configura o "algo" a ser articulado pelas estruturas semânticas. Puntel rejeita a semântica composicional e a ontologia da substância, fundadas no princípio composicional, e propõe uma nova perspectiva com base no princípio do contexto. A semântica e a ontologia contextuais adotam um tipo específico de sentenças teóricas que não são formadas por sujeito e predicado, a saber, as sentenças primas. Essas sentenças primas pressupõem o operador teórico "é o caso que", o qual é puramente teórico na medida em que considera o mundo enquanto tal.

De acordo com Puntel, o operador teórico "é o caso que", plenamente determinado, apresenta-se como o operador de verdade "é verdade(iro) que". Isso significa que é o conceito de verdade que expressa ou implica o estatuto completamente determinado da linguagem. A referência à "realidade" é a questão central, uma vez que o estatuto plenamente determinado da linguagem se refere à dimensão ontológica. A expressão máxima dessa tese é a concepção, defendida por Puntel, de verdade absoluta enquanto verdade em conformidade com todo e qualquer quadro teórico. Portanto, a concepção de verdade é a questão central para a determinação completa da linguagem e, consequentemente, para o desenvolvimento da filosofia sistemáticoestrutural de Lorenz Puntel.

\section{Referências}

Imaguire, G. 2008. Resenha de Struktur und Sein. Filosofia Unisinos 9(3): 284-92.

Oliveira, M. A. de. 2014. A ontologia em debate no pensamento contemporâneo. São Paulo: Paulus.

Puntel, L. B. 1993. The context principle, universals and primary states of affairs. American Philosophical Quarterly 30(2): 123-35.

- 1999. On the Logical Positivists' Theory of Truth: The Fundamental Problem and a New Perspective. Journal for General Philosophy of Science - Zeitschrift für Allgemeine Wissenschaftstheorie 30: 101-30.

Principia 19(3): 453-463 (2015). 
- 2001a. O conceito de categoria ontológica: um novo enfoque. Kriterion 104: 7-32.

- 2001b. Truth, Sentencial Non-Compositionality, and Ontology. Synthese 126: 221-59. . 2008. Estrutura e ser: um quadro referencial teórico para uma filosofia sistemática. Tradução de Nélio Schneider. São Leopoldo, RS: Ed. UNISINOS.

—. 2009. El concepto de verdad: esbozo de una teoría semántico-ontológica. Revista Portuguesa de Filosofia 65: 899-922.

- 2011. Ser e Deus: um enfoque sistemático em confronto com M. Heidegger, É. Lévinas e J.-L. Marion. Tradução de Nélio Schneider. São Leopoldo, RS: Ed. UNISINOS.

—. 2013. Observações críticas sobre uma resenha de Guido Imaguire da obra: Estrutura e Ser - um quadro referencial teórico para uma filosofia sistemática. Síntese 40(126): 43-72.

Quine, W. v. O. 1970. Philosophy of Logic. Englewoods Cliffs (NJ): Prentice-Hall. . 1990. Pursuit of Truth. Cambridge: Harvard University Press.

Tarski, A. 1983. The Concept of Truth in Formalized Languages. In: J. Corcoran (ed.) Logic, Semantics, Metamathematics, 2nd ed., p.152-278. Translated by J.H. Woodger. Indianapolis: Hackett. 